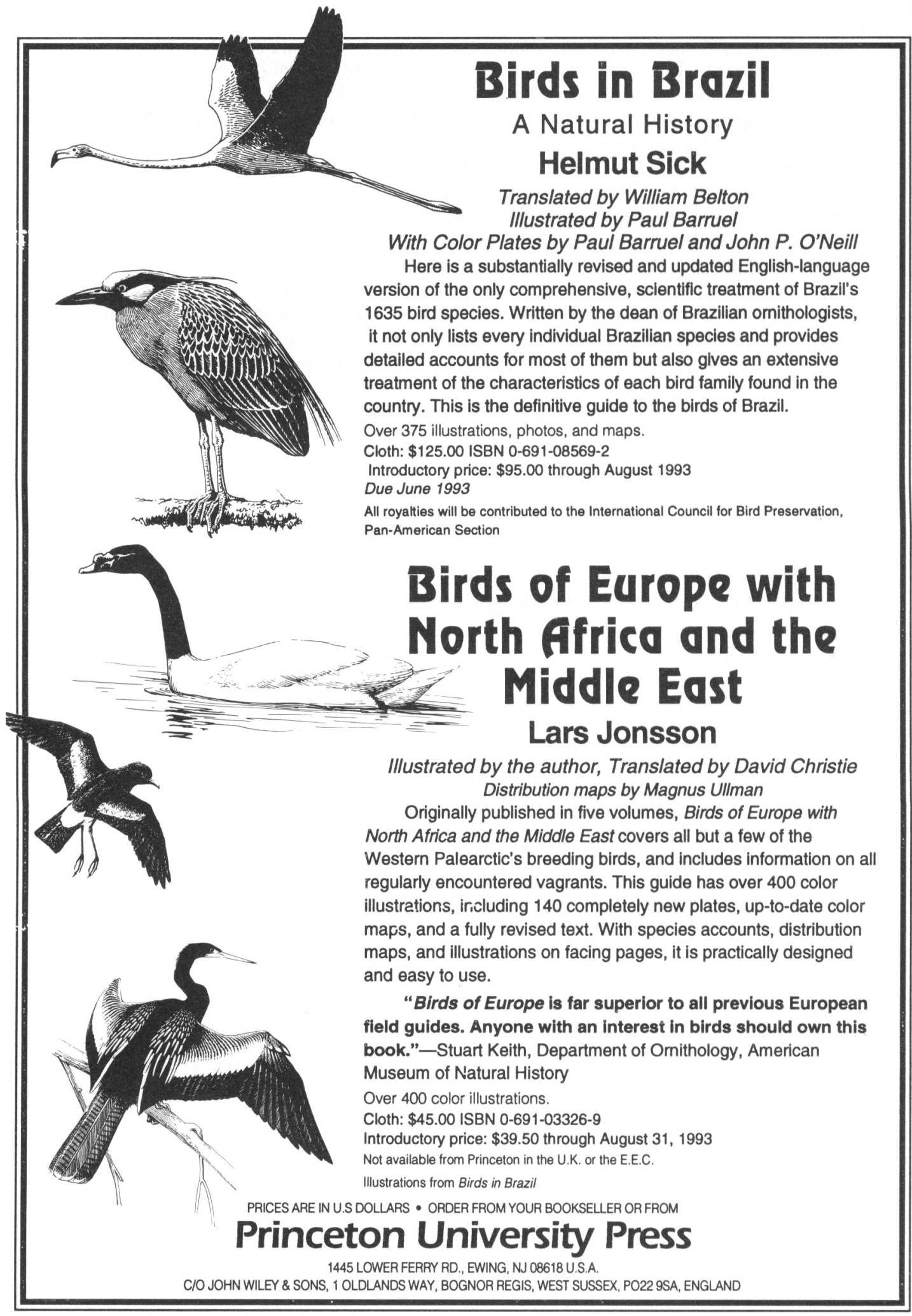




\section{BIOLOGICAL CONSERVATION}

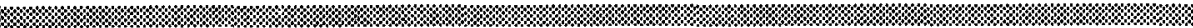

Editor-in-Chief: E. Duffey, Cergne House, Wadenhoe, Peterborough, UK

Editors: B.N.K. Davis, Monks Wood Experimental Station, Institute of Terrestrial Ecology, Abbots Ripton, Huntingdon, Cambridgeshire, UK, C.M. Schonewald-Cox, Institute of Ecology, University of California, Davis, California 95616, USA and

T.R. New, Department of Zoology, La Trobe University, Victoria, Australia

\section{Associate Editor: P. Fiedler, Department of Biology, San Francisco State University, USA}

Audience: Environmentalists, conservationists, botanists, marine scientists, ecologists, biologists. Your reliable source of information in a changing world

Why Subscribe?

Asubscription to Biological Conservation keeps you up-to-date with the most recent developments in your field. You will benefit from:

- reports of discoveries or important original information - analytical studies which contribute to our knowledge of conservation $\bullet$ frequent publication $\bullet$ papers independently refereed and published within 20 weeks of acceptance - large book review section surveying new literature available in the field I profiles of 'Contemporary Conservationists' who have made significant contributions in this area 'special issues' on topics of current interest and importance.

ABSTRACTED/INDEXED IN: Agricola Database, Biological and Agricultural Index, Current Advances in Ecological Sciences, Current Contents, Energy Information Abstracts, Environmental Periodicals Bibliography, Excerpta Medica (EMBASE), Geo Abstracts, Science Citation Index.

\section{SUBSCRIPTION INFORMATION}

ISSN 0006-3207

Frequency : 4 volumes in 12 issues.

Volumes 63-66 (1993): Worldwide delivery $£ 472.00$ / US\$756.00

All Subscriptions are airspeeded.

\section{SEND FOR A FREE SAMPLE COPY}

Orders and requests for sample copies should be sent to:

ELSEVIER SCIENCE PUBLISHERS LTD.,

Crown House, Linton Road, Barking, Esssex, IG11 8JU, UK.

for customers in North America

Elsevier Science Publishers, Journal Information Center, 655 Avenue of ther Americas, New York, NY 10010, U.S.A.

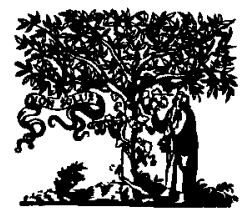




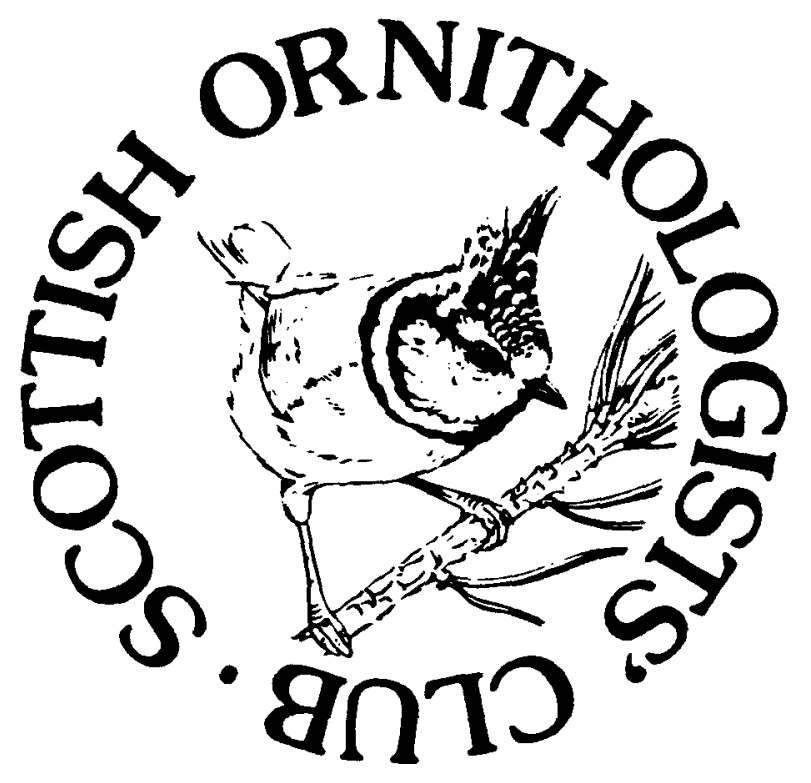

\section{SCOTTISH BIRDS}

\section{THE JOURNAL OF THE SCOTTISH ORNITHOLOGISTS' CLUB}

Members receive this highly-respected journal, the annual Scottish Bird Report and the quarterly Scottish Bird News. Branches throughout Scotland.

Details from:

21 Regent Terrace, Edinburgh EH7 5BT (tel 031-556 6042) 


\section{Guidelines for Contributors}

Bird Conservation International publishes papers and communications on subjects relevant to the conservation of birds, with a general preference for those addressing international or high national priorities. Submissions should be in duplicate, typewritten on one side of the paper only, and double-spaced, with positions of figures and tables indicated in the margin. Papers should be concise and factual, taking proper account of previous relevant literature opinions expressed should be based on adequate evidence. Titles of papers must be accurate and concise, and (for the benefit of abstraction services) include any relevant scientific (taxonomic) name; a running head is needed (the editors will provide this if authors do not). A full-length paper must include a proper summary. The use of a word processor is strongly advised.

Whenever possible, authors should consult an issue of $B C I$ for style and layout. Spelling generally follows The shorter Oxford English dictionary, supplemented by various standard references such as 'Topography' in $A$ dictionary of birds (1985) and the most recent edition of The Times atlas of the world. Localities with well-known other spellings or older names should have these placed in parentheses after first mention, while localities too small to be in the Times atlas should be given their precise geographical coordinates (preferably with some evidence of source).

Modern authorities should be followed for both English and scientific names of birds, with explanations of any deviation. On first mention of a bird both English and scientific name should be given, thereafter only one, preferably the English. Scientific trinomials need be used only if subspecific nomenclature is relevant to the topic under discussion. These recommendations also apply for any other animal or plant species mentioned.

Metric units and their international symbols should be used (other systems of measurement can be added in parentheses), with temperatures in the Centigrade (Celsius) scale. Numbers one to nine are written in full except when linked with a measurement abbreviation or higher number, thus 'five birds' but ' $5 \mathrm{~km}$ ' and '5-12 birds'; numerals are used for all numbers above ten, four-figure numbers and above using the comma thus: ' 1,234 ',

'12,345'. Details of experimental technique, extensive tabulations of results, etc., are best presented as appendices. Dates should be written 1 January 1985, times of day as 08h30, 17h55 (24-hour clock), etc. When citing a conversation ('verbally') or letter ('in litt.'), the contact's name and initials should be included, preferably with the year of communication. Maps are best marked with a scale and north arrow, and drawn very neatly. Good photographs are also considered. Captions for figures and photographs should be typed on a separate sheet.

References in the text should not use ampersand or comma before the date, and should be chronologically listed, alphabetically if in the same year. Publications by the same authors in the same year may be distinguished by $a, b$, etc., after the date. Full references must be listed alphabetically at the end in conformity with the existing system of presentation (which should be carefully checked before submission). Name(s) and postal address(es) of author(s) should appear at the end of the article, in the format adopted.

Authors will receive proofs for checking which they are required to return within three days of receipt. Proofs of joint papers will automatically go to the senior author. Textual changes in proof cannot normally be countenanced. Twenty-five reprints will be made available irrespective of number of authors, and sent to the senior author. 


\section{Volume 2 Number 4 December 1992}

\section{CONTENTS}

Censusing Laysan Ducks Anas laysanensis: a lesson in the pitfalls of estimating threatened species populations

ANN P. MARSHALL

Distribution, status and taxonomy of the near-threatened Black-bodied Woodpecker Dryocopus schulzi

A. MADROÑO NIETO AND M. PEARMAN

The conservation status of the birds of Negros, Philippines

THOMAS M. BROOKS, TOM D. EVANS, GUY C. L. DUTSON, GUY Q. A. ANDERSON, DESIDERIO C. ASANE, ROBERT J. TIMMINS AND ANGELA G. TOLEDO

Conservation status of birds on Mindoro, Philippines

GUY C. L. DUTSON, TOM D. EVANS, THOMAS M. BROOKS, DESIDERIO C. ASANE, ROBERT J.

TIMMINS AND ANGELA G. TOLEDO

Status, distribution and ecology of the White-breasted Parakeet Pyrrhura albipectus in Podocarpus National Park, southern Ecuador

E. P. TOYNE, M. T. JEFFCOTE AND J. N. FLANAGAN

\section{Cambridge University Press}

The Pitt Building, Trumpington Street, Cambridge CB2 1RP

40 West 20th Street, New York, NY 10011-4211, USA

10 Stamford Road, Oakleigh, Melbourne 3166, Australia 